\title{
Catalytic ozonation of toxic pollutants over magnetic cobalt-doped $\mathrm{Fe}_{3} \mathrm{O}_{4}$ suspensions
}

\author{
Aihua Lv, Chun Hu*, Yulun Nie, Jiuhui Qu \\ State Key Laboratory of Environmental Aquatic Chemistry, Research Center for Eco-Environmental Sciences, Chinese Academy of Sciences, Beijing 100085, China
}

\section{A R T I C L E I N F O}

\section{Article history:}

Received 23 October 2011

Received in revised form 17 January 2012

Accepted 19 January 2012

Available online 28 January 2012

\section{Keywords:}

Adsorption of ozone

Magnetic catalyst

Multivalence

Redox

Toxic pollutant

\begin{abstract}
A B S T R A C T
Magnetic cobalt-doped $\mathrm{Fe}_{3} \mathrm{O}_{4}$ (FeCo) was prepared using a co-precipitation method and characterized by X-ray diffraction (XRD), X-ray photoelectron spectroscopy (XPS), cyclic voltammetry (CV), and in situ attenuated total reflection Fourier transform infrared (ATR-FTIR) spectroscopy. The catalyst showed high, stable catalytic activity for the degradation and mineralization of toxic persistent organic pollutants, as demonstrated with the herbicides 2,4-dichlorophenoxyacetic acid, 2,4-dichlorophenol, and 2,4,6-trichlorophenol and pharmaceutical phenazone in aqueous solution with ozone. FeCo was very effective at the mineralization of refractory oxalic acid produced in the degradation of organic compounds. The ozone was adsorbed on the surface of FeCo competing with water molecules in the aqueous phase, and converted into hydroxyl radical, meanwhile the catalyst surface underwent oxidation and reduction as demonstrated by in situ ATR-FTIR, CV and other experimental data obtained. Furthermore, the characterization studies indicated that the introduction of Co increased the rate of FeCo oxidation and reduction during the decomposition of ozone, enhancing the activity and stability of $\mathrm{Fe}_{3} \mathrm{O}_{4}$.
\end{abstract}

(c) 2012 Elsevier B.V. All rights reserved.

\section{Introduction}

Industrial and municipal wastewater containing numerous chemicals in varying concentrations flows or seeps into rivers, lakes, groundwater, and coastal seas. Consequently, approximately 300 million tons of synthetic compounds used in industrial and consumer products find their way into natural waters annually. The increasing worldwide contamination of freshwater with thousands of industrial and natural chemicals is a major environmental problem facing humanity. Although most of these compounds are present at low concentrations, many of them raise considerable toxicological concerns, particularly when present as components of complex mixtures. A major future challenge in wastewater and drinking-water treatment is to improve existing unit processes and to design new ones to remove a large number of very different micropollutants from a broad range of water matrices [1].

Recently, catalytic ozonation has attracted significant attention as an effective process for removing organics from water. It was developed to overcome the limitations of ozonation processes, such as the formation of by-products and selective reactions of ozone $[2,3]$. Supported and unsupported metals and metal oxides are the catalysts most commonly tested for the ozonation of organic compounds in water [4,5]. Despite these promising studies, one obstacle

\footnotetext{
* Corresponding author. Tel.: +86 10 62849628; fax: +861062923541.

E-mail address: huchun@rcees.ac.cn (C. Hu).
}

to the practical application of catalytic ozonation is the separation of these catalysts from the treated water. The application of magnetic particle technology to solve environmental problems has received considerable attention in recent years [6-8]. Magnetic particles can be separated from a medium using a simple magnetic process. Previously, we studied the use of magnetic iron oxides for the catalytic ozonation of organic pollutants in water. Cobalt and manganese co-doped $\gamma-\mathrm{Fe}_{2} \mathrm{O}_{3}$ efficiently mineralized toxic pollutants in water [9]. However, the release of metal ions (iron, cobalt, and manganese) decreased the stability and activity of the catalyst. Studies have verified that transition metal oxides with multiple readily accessible oxidation states are good catalysts for ozone decomposition [9-11]. Therefore, the multivalence and stability of the catalyst are crucial for catalytic ozonation in water.

The decomposition mechanism of gaseous ozone has been elucidated with in situ Raman spectroscopy and isotopic substitution $[12,13]$. The main redox steps were involved in the formation of superoxide or peroxide species on the surfaces of metal oxides. Bulanin et al. [14] suggested that ozone dissociates after adsorption on strong Lewis sites yielding a surface oxygen atom, whereas on weaker sites, ozone molecules coordinate via one of the terminal oxygen atoms. With regard to the bulk aqueous phase, the catalytic ozonation mechanism is still controversial because the pathway is so complex, but in the heterogeneous catalytic ozonation process, adsorption of ozone and its further decomposition are generally believed to lead to surface-bound O-radicals and hydroxyl 
radicals on the surfaces of catalysts [15-17]. In addition, verification of the mechanisms governing catalytic ozonation is particularly problematic, as the use of catalysts in aqueous solutions will lead to competition between water, ozone, and organic compounds for the catalytic (adsorptive) active sites. The process of aqueous ozone decomposition can be affected by the ability of the catalyst to adsorb and desorb $\mathrm{O}_{3}$, the activity of the oxygen species, and ability to desorb $\mathrm{O}_{2}$ [18]. It is very difficult to prove the adsorption of ozone on solid surfaces in an aqueous medium; consequently, no comprehensive discussion of this has been published. All of the adsorptive centers relevant to the catalytic processes have a high affinity for water. However, ozone might be highly basic, resulting in strong affinity to Lewis acid sites on the surface of metal oxides due to its unique structural properties and the high electron density on one of the oxygen atoms. Therefore, it is very likely that ozone adsorption/decomposition occurs at the active surface sites.

Unfortunately, there is no direct evidence of ozone adsorption on metal oxides in the presence of water. An understanding of the mechanisms of hydroxyl radical formation during catalytic ozonation is vital to developing this technique for water treatment on an industrial scale.

Here, cobalt substituted $\mathrm{Fe}_{3} \mathrm{O}_{4}$ (FeCo) catalysts were prepared using a co-precipitation method. The herbicide 2,4dichlorophenoxyacetic acid (2,4-D) and its derivative 2,4dichlorophenol (2,4-DCP), together with 2,4,6-trichlorophenol (2,4,6-TCP) and pharmaceutical phenazone (PZ), which have been studied in catalytic ozonation in previous works [10,19-22], were selected to evaluate the activity and properties of the catalysts with ozone in aqueous solution. Cobalt-doped $\mathrm{Fe}_{3} \mathrm{O}_{4}$ showed highly efficiency and stability for the degradation and mineralization of the selected pollutants. For the first time, the competitive adsorption of $\mathrm{O}_{3}$ with $\mathrm{D}_{2} \mathrm{O}$ was observed at the surface of FeCo in the aqueous phase under different conditions using in situ attenuated total reflection Fourier transform infrared (ATR-FTIR) spectroscopy. A hydroxyl radical reaction mechanism was verified for the catalytic ozonation of selected pollutants in the FeCo suspension with ozone.

\section{Experimental}

\subsection{Materials and reagents}

The 2,4-D, 2,4-DCP, 2,4,6-TCP and para-chlorobenzoic acid ( $p C B A)$ were obtained from Yili Fine Chemicals (Beijing, China) and PZ was purchased from Acros (Geel, Belgium). Their purities were higher than $99 \%$. Ferric nitrate, cobalt nitrate and ammonium acetate which are analytical grade were purchased from Beijing Chemical Reagent Company (Beijing, China). All solutions were prepared with deionized water. The initial $\mathrm{pH}$ of the solutions was adjusted with $\mathrm{HCl}$ or $\mathrm{NaOH}$.

\subsection{Catalyst preparation}

Magnetite $\left(\mathrm{Fe}_{3} \mathrm{O}_{4}\right)$ was prepared from the precipitate of ferric nitrate solution with aqueous sodium hydroxide, as described previously [23]. The precipitate was washed with ammonium acetate solution, dried at $100^{\circ} \mathrm{C}$ for $12 \mathrm{~h}$, and treated at $400^{\circ} \mathrm{C}$ under an atmosphere of $\mathrm{N}_{2}$ for $2 \mathrm{~h}$. The Co-substituted magnetite $\mathrm{Fe}_{3-x} \mathrm{Co}_{x} \mathrm{O}_{4}$ $(x=0.1,0.3$ and 1$)$ was prepared as described above with the addition of cobalt nitrate. The catalyst $\mathrm{Fe}_{2.7} \mathrm{Co}_{0.3} \mathrm{O}_{4}$ performed the best (designated $\mathrm{FeCo}$ ) and was used for all subsequent experiments. As a reference, $\alpha-\mathrm{Fe}_{2} \mathrm{O}_{3}$ was prepared by the same method, except that the precipitate was washed with deionized water, dried at $100^{\circ} \mathrm{C}$, and calcined at $550^{\circ} \mathrm{C}$ for $5 \mathrm{~h}$ in air.

\subsection{Characterization}

Powder X-ray diffraction (XRD) of the catalyst was recorded on a XDS 2000 Diffractometer (Scintag Inc., CA) with $\mathrm{Cu} \mathrm{K \alpha}$ radiation $(\lambda=1.54059 \AA)$. Magnetic measurements were conducted on a 7307 vibrating sample magnetometer (Lake Shore Cryotronics Inc., USA). The X-ray photoelectron spectroscopy (XPS) data were taken on an AXIS Ultra instrument (Kratos Analytical, UK) using monochromatic $\mathrm{Al} \mathrm{K \alpha}$ radiation $(225 \mathrm{~W}, 15 \mathrm{~mA}, 15 \mathrm{kV})$. Transmission electron microscopy (TEM) images of the catalysts were obtained using a TEM H-7500 (Hitachi, Japan). The zeta potential of the catalysts in the $\mathrm{KNO}_{3}\left(10^{-3} \mathrm{M}\right)$ solution was measured with a Zetasizer 2000 (Malvern, UK), obtaining three consistent readings. The acid groups were determined following the method proposed by Boehm [24].

Electrochemical experiments were performed on a basic electrochemical system (Princeton Applied Research Co., U.S.A.). All experiments were done using a three-electrode cell configuration with a catalyst modified conductive glass (prepared by dip coating and drying in air at $70^{\circ} \mathrm{C}$ ) as the working electrode, a platinum wire as the auxiliary electrode and a saturated calomel electrode as the reference electrode.

\subsubsection{In situ ATR-FTIR spectroscopy}

The desired amount of catalyst particles was added to $\mathrm{D}_{2} \mathrm{O}$ and sonicated; the initial pD was adjusted to 6 with $\mathrm{DCl}$. Then, gaseous $\mathrm{O}_{3} 30 \mathrm{mg} \mathrm{L}^{-1}$ (oxygen-ozone) was bubbled into a $5 \mathrm{~mL}$ centrifuge tube containing $2 \mathrm{~mL} \mathrm{D}_{2} \mathrm{O}$ and $0.1 \mathrm{~g}$ catalyst at an initial $\mathrm{pD}$ of 6 for different times. The sample was sealed and centrifuged immediately: half of the supernatant was used as the reference, and the solid resuspended in the other half was used as the sample. This procedure yielded a solid concentration of $100 \mathrm{~g} \mathrm{~L}^{-1}$. In the experiment with pollutants, 2,4-D was quickly added to the $\mathrm{O}_{3}$ saturated sample, sealed, shaken vigorously for $5 \mathrm{~min}$, and then centrifuged and measured using the same procedure. The ATR-FTIR spectra were recorded using a TENSOR 27 infrared spectrometer with a DLaTGS detector and a ZnSe horizontal ATR cell. Infrared spectra in the range of $4000-650 \mathrm{~cm}^{-1}$ were obtained by averaging 32 scans with a resolution of $4 \mathrm{~cm}^{-1}$ at room temperature. The all presented spectra were difference spectra between the spectrum of the suspension and the spectrum of the supernatant.

\subsection{Procedures and analysis}

Semi-batch experiments were carried out with a $1.2 \mathrm{~L}$ reactor. The reaction temperature was maintained at $20^{\circ} \mathrm{C}$. In a typical experiment, $1 \mathrm{~L}$ of $20 \mathrm{mg} \mathrm{L}^{-1}$ 2,4-D aqueous solution was introduced into the reactor. $1 \mathrm{~g}$ catalyst was added into this solution under magnetically stir. $30 \mathrm{mg} \mathrm{L}^{-1}$ gaseous $\mathrm{O}_{3}$ oxygen-ozone was then bubbled into the reactor through the porous plate of the reactor bottom at a $12 \mathrm{~L} \mathrm{~h}^{-1}$ flow rate. Ozone gas was generated by a 3S-A5 laboratory ozonizer (Tonglin Technology, China). The residual ozone in the off-gas was adsorbed by a KI solution. Samples were withdrawn at given intervals. After the residual ozone was instantly quenched with $0.1 \mathrm{M} \mathrm{Na}_{2} \mathrm{~S}_{2} \mathrm{O}_{3}$, each sample was filtered through a $0.45 \mu \mathrm{m}$ cellulose acetate membrane for analysis. The gaseous ozone concentration was measured using iodometry. The total organic carbon (TOC) of each solution was analyzed with a Phoenix 8000 TOC analyzer (Tekmar-Dohrmann, U.S.A.). The oxalic acid concentrations were determined with an 861 ion chromatograph (Metrohm, Switzerland). A U-3100 UV-vis spectrophotometer (Hitachi, Japan) was used to measure the aqueous solution adsorbance. The $p$ CBA concentrations were determined using a 1200 series HPLC (Agilent, USA). The amounts of $\mathrm{Fe}^{3+}$ and $\mathrm{Co}^{2+}$ leaching from the catalyst during the reaction were measured by inductively coupled plasma optical emission spectrometry (ICP-OES) on an OPTIMA 2000 (PerkinElmer, USA). Gas 




Fig. 1. XRD patterns of the different catalysts: (a) $\mathrm{Fe}_{3} \mathrm{O}_{4}$, (b) FeCo.

chromatography-mass spectrometry (GC-MS) analysis was used to determine the byproducts of 2,4-D degradation.

The experiments of $\mathrm{O}_{3}$ decomposition were carried out in sealed three-mouth $260 \mathrm{~mL}$ bottle. The gaseous $\mathrm{O}_{3} 30 \mathrm{mg} \mathrm{L}^{-1}$ (oxygen-ozone) was bubbled into the reactor to get $200 \mathrm{~mL} \mathrm{O}_{3}$ saturated aqueous solution (about $4 \mathrm{mg} \mathrm{L}^{-1}$ ) with $60 \mathrm{~mL}, 30 \mathrm{mg}$ of gaseous $\mathrm{O}_{3} /$ L oxygen-ozone mixture gas above solution. $0.1 \mathrm{~g}$ catalyst was added into the reactor and stirred magnetically. At given time intervals, the concentration of residual ozone in aqueous solution was monitored by UV spectrophotometer using the indigo method.

\section{Results and discussion}

\subsection{Characterization of catalysts}

Fig. 1 shows the XRD patterns of iron oxide and Co-substituted iron oxide. The pure spinel crystalline phase was observed in both samples, which exhibited six characteristic peaks at $2 \theta$ around $30.1^{\circ}, 35.5^{\circ}, 43.1^{\circ}, 53.4^{\circ}, 57.0^{\circ}$, and $62.6^{\circ}$. Therefore, $\mathrm{Fe}_{3} \mathrm{O}_{4}$ or $\gamma$ $\mathrm{Fe}_{2} \mathrm{O}_{3}$ was the main crystalline phase. As shown in Fig. 2A, the binding energies (BE) of Fe $2 \mathrm{p}_{3 / 2}$ were 710.7 and $710.8 \mathrm{eV}$ for $\mathrm{FeCo}$ and iron oxide respectively, suggesting the existence of the $\mathrm{Fe}_{3} \mathrm{O}_{4}$ phase based on the standard $\mathrm{Fe} 2 \mathrm{p}_{3 / 2} \mathrm{BE}$ of $\mathrm{Fe}^{2+}(709.5 \mathrm{eV})$ and $\mathrm{Fe}^{3+}$ $(711.2 \mathrm{eV})$ and the $\mathrm{Fe} 2 \mathrm{p}_{3 / 2} \mathrm{BE}$ data of $\mathrm{Fe}_{3} \mathrm{O}_{4}[25,26]$. During the preparation of iron oxide, $\mathrm{Fe}^{3+}$ was partly reduced to $\mathrm{Fe}^{2+}$ by the residual ammonium acetate in the precipitate during calcination. The same results have been obtained previously [23]. The Co 2p XPS spectrum of FeCo (Fig. 2B) contained two main peaks at 780.3 and
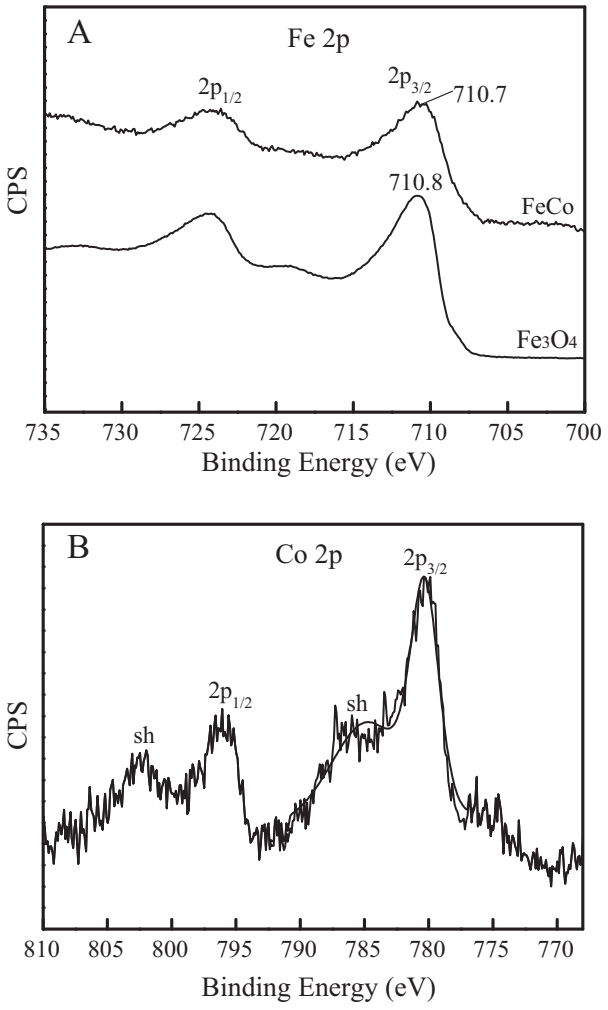

Fig. 2. XPS spectra of $\mathrm{FeCo}$ and $\mathrm{Fe}_{3} \mathrm{O}_{4}$ : (A) Fe 2p, (B) Co 2p.

796.2 eV for Co $2 \mathrm{p}_{3 / 2}$ and Co $2 \mathrm{p}_{1 / 2}$, respectively, with corresponding satellite peaks at their high-energy sides, which were assigned to the $\mathrm{Co}$ (II) species [27]. The crystal sizes of $\mathrm{Fe}_{3} \mathrm{O}_{4}$ and FeCo were 24.5 and $23.2 \mathrm{~nm}$, respectively, based on calculation with Scherrer's equation, and were in good agreement with the crystallite sizes estimated from the TEM micrographs (Fig. 3).

The magnetization curve of $\mathrm{Fe}_{3} \mathrm{O}_{4}$ exhibited a small hysteresis loop, demonstrating that it was weakly ferromagnetic (Fig. 4), while a conspicuous hysteresis loop was observed for $\mathrm{FeCo}$, indicating that FeCo possessed relatively greater ferromagnetic behavior. The saturation magnetization values were 66.3 and $65.6 \mathrm{emu} \mathrm{g}^{-1}$ for $\mathrm{Fe}_{3} \mathrm{O}_{4}$ and $\mathrm{FeCo}$, respectively. The $\mathrm{pH}$ points of zero charge $\left(\mathrm{pH}_{\mathrm{pzc}}\right)$ were 6.4 and 6.6, while the surface acid group contents were 200.4 and $218.9 \mu \mathrm{mol} \mathrm{g}^{-1}$ for $\mathrm{Fe}_{3} \mathrm{O}_{4}$ and $\mathrm{FeCo}$, respectively (Table 1). The

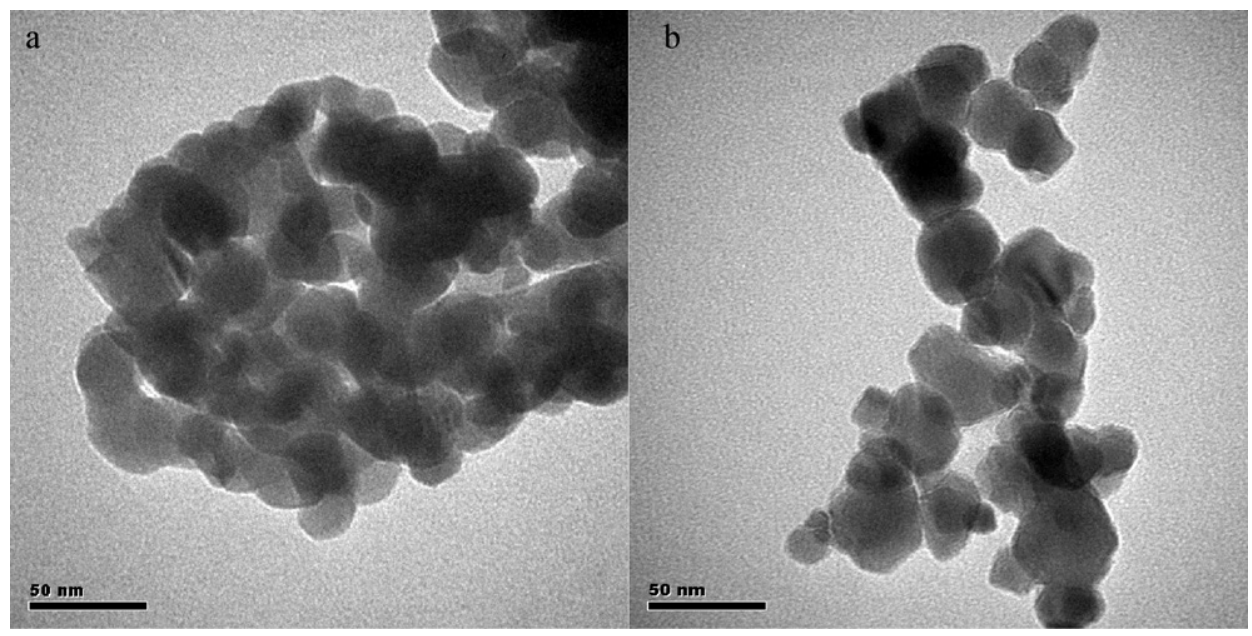

Fig. 3. TEM image of $\mathrm{Fe}_{3} \mathrm{O}_{4}$ (a) and $\mathrm{FeCo}$ (b) particles. 
Table 1

Textural properties of $\mathrm{Fe}_{3} \mathrm{O}_{4}$ and $\mathrm{FeCo}$.

\begin{tabular}{|c|c|c|c|c|}
\hline Samples & Particle size $(\mathrm{nm})$ & $\mathrm{pH}_{\mathrm{PZC}}$ & Acid groups $\left(\left(\mathrm{mol} \mathrm{g}^{-1}\right)\right.$ & Saturation magnetization $\left(\mathrm{emu}^{-1}\right)$ \\
\hline $\mathrm{Fe}_{3} \mathrm{O}_{4}$ & 24.5 & 6.4 & 200.4 & 66.3 \\
\hline $\mathrm{FeCo}$ & 23.2 & 6.6 & 218.9 & 65.6 \\
\hline
\end{tabular}



Fig. 4. Room-temperature magnetization loops of $\mathrm{Fe}_{3} \mathrm{O}_{4}$ and $\mathrm{FeCo}$.

results indicated that the addition of Co did not change the surface acidic-basic properties of $\mathrm{Fe}_{3} \mathrm{O}_{4}$ very much.

\subsection{Catalytic ozonation of pollutants}

\subsubsection{Activity and stability of catalysts}

The activities of different catalysts were evaluated via the mineralization of 2,4-D with ozone at an initial $\mathrm{pH}$ of 6 . The 2,4-D showed minimal adsorption on $\mathrm{Fe}_{3} \mathrm{O}_{4}, \mathrm{FeCo}$, and $\alpha-\mathrm{Fe}_{2} \mathrm{O}_{3}$ under the experimental conditions. As shown in Fig. 5, about 33\% of the TOC was removed in a 20 min reaction in the $\alpha-\mathrm{Fe}_{2} \mathrm{O}_{3}$ suspension with ozone, which was almost the same as in ozone alone. By contrast, the mineralization rate was greatly enhanced in the $\mathrm{Fe}_{3} \mathrm{O}_{4}$ and $\mathrm{FeCo}$ suspensions under otherwise identical conditions; about $60 \%$ and $93 \%$ of the TOC was removed, respectively, at $20 \mathrm{~min}$. In comparison, $33 \%$ of the TOC was removed from the $\mathrm{Fe}^{3+} 0.062 \mathrm{mg} \mathrm{L}^{-1}$ and $\mathrm{Co}^{2+}$ $0.111 \mathrm{mg} \mathrm{L}^{-1}$ (the highest concentration detected in FeCo during the reaction) solutions with ozone, so the catalytic contribution of the released ions was not predominant in the reaction system. The three catalysts showed different activities, which decreased gradually in the following order: $\mathrm{FeCo}>\mathrm{Fe}_{3} \mathrm{O}_{4}>\alpha-\mathrm{Fe}_{2} \mathrm{O}_{3}$. Therefore, the activity of a solid catalyst in aqueous solution is related to multiple components and the multivalence of the metal. The mechanism

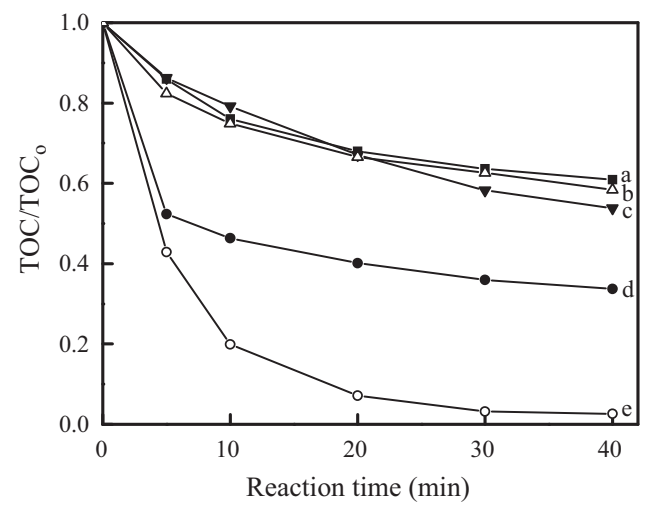

Fig. 5. Removal of TOC during the degradation of 2,4-D in aqueous dispersions of various catalysts with ozone: (a) no catalyst, (b) $\alpha-\mathrm{Fe}_{2} \mathrm{O}_{3}$, (c) $\mathrm{Fe}^{3+}\left(0.062 \mathrm{mg} \mathrm{L}^{-1}\right)$ and $\mathrm{Co}^{2+}\left(0.111 \mathrm{mg} \mathrm{L}^{-1}\right)$ from $\mathrm{FeCo}$, (d) $\mathrm{Fe}_{3} \mathrm{O}_{4}$, (e) FeCo (initial $\mathrm{pH}: 6,2$,4-D: $20 \mathrm{mg} \mathrm{L}^{-1}$, catalyst: $1 \mathrm{~g} \mathrm{~L}^{-1}$, gaseous ozone concentration: $\left.30 \mathrm{mg} \mathrm{L}^{-1}\right)$. of gaseous ozone decomposition consists mainly of redox steps: the adsorption of ozone on the catalyst and the desorption of the adsorbed intermediates [18]. The multiple oxidation states of transition metal oxides were useful for the catalyst to undergo oxidation and reduction, enhancing the decomposition of ozone. Therefore, the results suggest that the same procedure might occur in the catalyst aqueous suspension with ozone. The coexistence of $\mathrm{Fe}^{2+}$ and $\mathrm{Fe}^{3+}$ in $\mathrm{Fe}_{3} \mathrm{O}_{4}$ and $\mathrm{Fe}^{2+}, \mathrm{Fe}^{3+}$, and $\mathrm{Co}^{2+}$ in $\mathrm{FeCo}$ increased the oxidation and reduction involved in the decomposition of ozone. The rate of ozone decomposition was obviously enhanced in the catalyst suspensions (Fig. 6), paralleling the TOC removal in these systems. Furthermore, the cyclic voltammetry (CV) behaviors of FeCo, $\mathrm{Fe}_{3} \mathrm{O}_{4}$, and $\alpha-\mathrm{Fe}_{2} \mathrm{O}_{3}$ film electrodes were investigated in a $0.1 \mathrm{M} \mathrm{Na}_{2} \mathrm{SO}_{4}$ solution under an air or ozone atmosphere. As shown in Fig. 7 , no obvious current was observed at the $\alpha-\mathrm{Fe}_{2} \mathrm{O}_{3}$ electrode, while there appeared current with different extents at the $\mathrm{Fe}_{3} \mathrm{O}_{4}$ and $\mathrm{FeCo}$ electrode. The results indicated that there was surface charge on $\mathrm{Fe}_{3} \mathrm{O}_{4}$ and $\mathrm{FeCo}$. With the addition of ozone, a reducing current was observed with the $\mathrm{Fe}_{3} \mathrm{O}_{4}$ and $\mathrm{FeCo}$ electrodes, verifying that the reduction reaction occurred on the surface of the catalyst with the decomposition of $\mathrm{O}_{3}$. In general conditions cobalt exhibits the redox pairs $\mathrm{Co}^{2+} / \mathrm{Co}^{3+}$, ozone can oxidize $\mathrm{Co}_{\text {surf }}^{2+}$ in $\mathrm{FeCo}$ to $\mathrm{Co}_{\text {surf }}^{3+}$ considering the standard reduction potentials $E^{\circ}\left(\mathrm{Co}^{3+} / \mathrm{Co}^{2+}\right)=1.81 \mathrm{~V}$ and $E^{\circ}\left(\mathrm{O}_{3} / \mathrm{O}_{2}\right)=2.07 \mathrm{~V}$, and then the $\mathrm{Fe}_{\text {surf }}^{2+}$ in $\mathrm{FeCo}$ can reduce the $\mathrm{Co}_{\text {surf }}^{3+}$ to its initial state of $\mathrm{Co}_{\text {surf }}^{2+}\left(E^{\circ}\left(\mathrm{Fe}^{3+} / \mathrm{Fe}^{2+}\right)\right)=0.77 \mathrm{~V}$, while the $\mathrm{Fe}_{\text {surf }}^{2+}$ oxidized to $\mathrm{Fe}_{\text {surf }}^{3+}$ can reduce to its initial state by $\cdot \mathrm{OOH}$ : $\mathrm{Fe}_{\text {surf }}^{3+}+\cdot \mathrm{OOH} \rightarrow \mathrm{Fe}_{\text {surf }}^{2+}+\mathrm{O}_{2}+\mathrm{H}^{+}$. Therefore, the efficient regeneration of $\mathrm{Co}^{2+}$ surface species by this process would be responsible for the remarkable increase on the activity of organic oxidation observed.

Moreover, the activity of FeCo did not decrease markedly after six successive cycles of 2,4-D degradation testing, as shown in Fig. S1 (Supporting Information). XRD determined that the FeCo did not undergo any phase changes after six successive reactions, whereas phase changes to hematite occurred in the pure $\mathrm{Fe}_{3} \mathrm{O}_{4}$ because of oxidation after only one $40 \mathrm{~min}$ reaction (Fig. S2, Supporting Information). In addition, the magnetization of $\mathrm{Fe}_{3} \mathrm{O}_{4}$ decreased to an extent after a 40 min reaction, while the magnetization of FeCo did not change significantly after six successive reactions (Fig. S3, Supporting Information). XPS indicated that the $\mathrm{BE}$ of $\mathrm{Fe} 2 \mathrm{p}_{3 / 2}$ in FeCo was still $710.7 \mathrm{eV}$ after the reaction, while

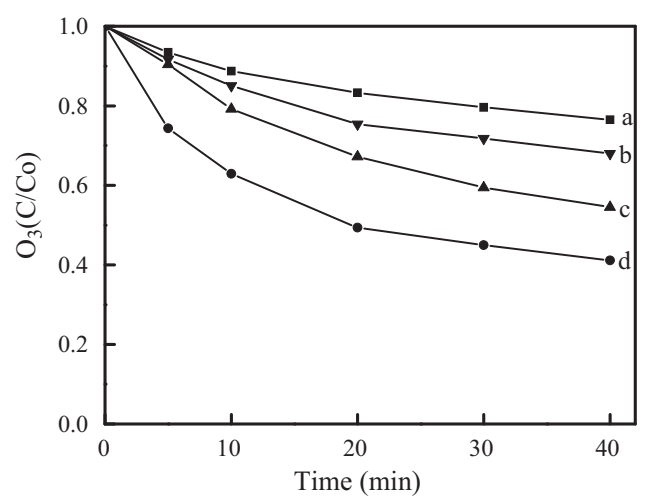

Fig. 6. Decomposition of ozone in aqueous dispersions of various catalysts: (a) without catalyst, (b) $\alpha-\mathrm{Fe}_{2} \mathrm{O}_{3}$, (c) $\mathrm{Fe}_{3} \mathrm{O}_{4}$, (d) FeCo. 

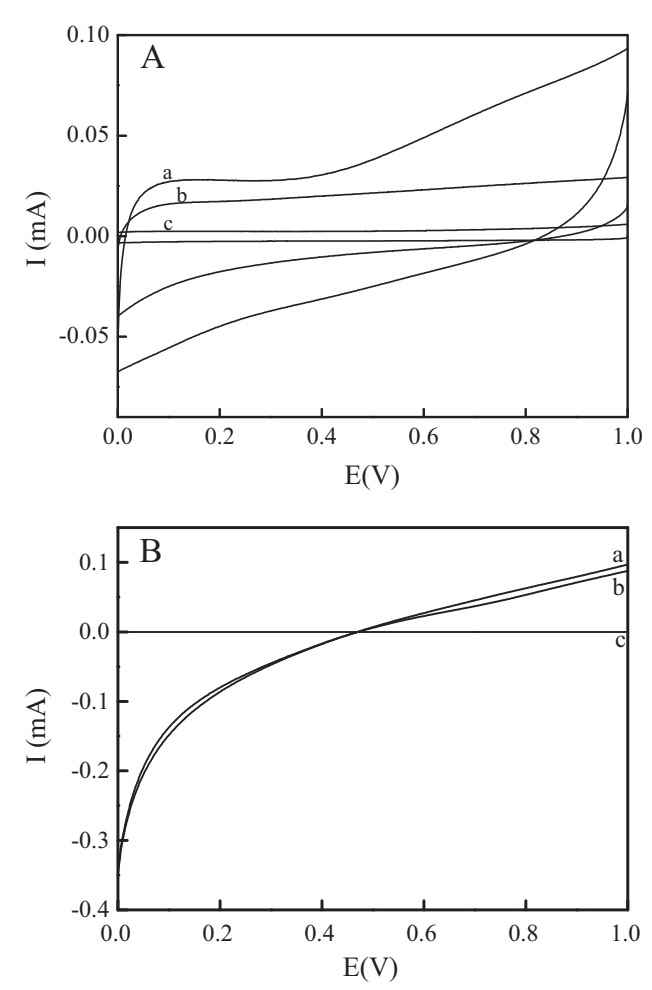

Fig. 7. Cyclic voltammetry scans with (a) $\mathrm{FeCo}$, (b) $\mathrm{Fe}_{3} \mathrm{O}_{4}$, and (c) $\alpha-\mathrm{Fe}_{2} \mathrm{O}_{3}$ electrodes in air-saturated $0.1 \mathrm{M}$ sodium sulfate aqueous solution without (A) and with (B) ozone. Scan rate: $30 \mathrm{mV} \mathrm{s}^{-1}$.

the $\mathrm{BE}$ of $\mathrm{Co} 2 \mathrm{p}_{3 / 2}$ increased from 780.3 to $780.57 \mathrm{eV}$, indicating that $\mathrm{Co}^{2+}$ was partly oxidized to $\mathrm{Co}^{3+}$ during the decomposition of $\mathrm{O}_{3}$ on the surface of the catalyst (Fig. S4, Supporting Information). The coexistence of $\mathrm{Co}^{2+}$ and $\mathrm{Co}^{3+}$ increased the multiple oxidation states of the transition metal oxides, enhancing the oxidation and reduction reactions on the catalyst surface, resulting in greater activity and stability of the catalyst during catalytic ozonation.

\subsubsection{Degradation and mineralization of other pollutants}

Single ozonation and catalytic ozonation removed 2,4-D and produced $\mathrm{Cl}^{-}$at the same efficiency $[8,10]$. However, for the further degradation of intermediates, such as carboxylic acids, the oxidation performance of ozone was insufficient, while FeCo with ozone had significantly enhanced activity. The $\mathrm{pH}$ always decreased because of the formation and accumulation of small carboxylic acids in the system based on ozone alone, while the $\mathrm{pH}$ decreased to 4.2 within $5 \mathrm{~min}$, and then increased to 5.3 at $40 \mathrm{~min}$ in the FeCo suspension with ozone, reflecting the prompt production and degradation of carboxylic acids. Moreover, the UV/visible results of 2,4-D degradation were shown in Fig. S5 (Supporting Information). Before treatment, the UV-vis spectra of 2,4-D have two main adsorption bands in the UV region (230 and $284 \mathrm{~nm}$ ). At a reaction time of $5 \mathrm{~min}$, the intensity of the adsorption bands became weakly, especially in the process of catalytic ozonation with FeCo. As the reaction proceeded, the UV-vis adsorption bands in the catalytic ozonation system became very weak while in the single ozonation system there was still some adsorption at $258 \mathrm{~nm}$. These results were consistent with the time course of TOC removal. The GC-MS analysis indicated that the major byproducts were ethylene glycol, glycolic acid, and oxalic acid after the $40 \mathrm{~min}$ reaction in ozone alone, while only the first two appeared in the FeCo suspension with ozone (Table S1, Supporting Information). Fig. 8 shows the production of oxalic acid in different reaction systems according

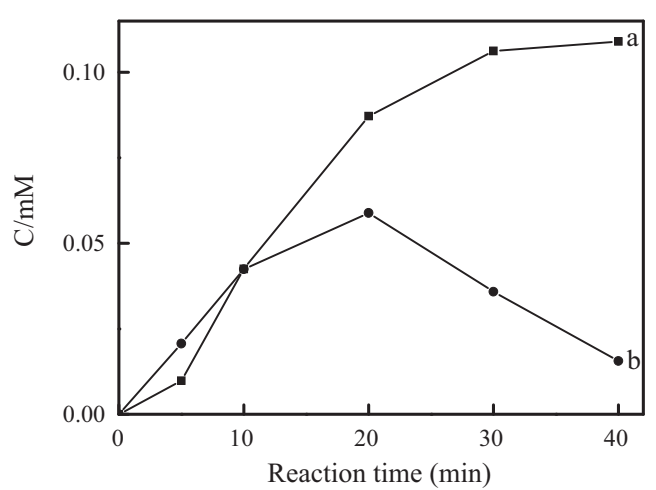

Fig. 8. The change in oxalic acid concentration during the degradation of 2,4-D with ozone: (a) no catalyst, (b) FeCo (initial pH: 6, 2,4-D: $20 \mathrm{mg} \mathrm{L}^{-1}$, catalyst: $1 \mathrm{~g} \mathrm{~L}^{-1}$, gaseous ozone concentration: $30 \mathrm{mg} \mathrm{L}^{-1}$ ).

to the reaction time. The amount of oxalic acid increased gradually and reached a peak in the reaction with ozone alone, whereas in the FeCo suspension with ozone, the oxalic acid concentration increased to a maximum, and then decreased gradually, which also matched the TOC removal.

In addition, 79,98 , and $98 \%$ of the pharmaceutical $\mathrm{PZ}$ and the pesticides 2,4-DCP and 2,4,6-trichlorophenol (2,4,6-TCP), respectively, were mineralized in the FeCo suspension with ozone at $40 \mathrm{~min}$, while the corresponding TOC removals were 39,62, and $47 \%$, respectively, with ozone alone (Fig. S6, Supporting Information).

\subsection{Catalytic ozonation mechanism in FeCo suspension}

Activity and cyclic voltammetry studies of the catalysts indicated that FeCo underwent oxidation and reduction during the decomposition of ozone. A similar process of ozone decomposition might occur in the FeCo aqueous suspension as the decomposition of gaseous ozone over catalyst, including adsorption of ozone and desorption of the adsorbed intermediates on the catalyst. To prove this conjecture, in situ ATR-FTIR experiments were carried out under different conditions in aqueous FeCo suspensions. In these experiments, $\mathrm{D}_{2} \mathrm{O}$ was used as the solvent instead of $\mathrm{H}_{2} \mathrm{O}$ to distinguish it from the bulk $\mathrm{OH}$ of the catalyst. As shown in Fig. 9, the peaks at 2260 and $1158 \mathrm{~cm}^{-1}$ were assigned to the vibrations of hydrogen-bonded $\mathrm{D}_{2} \mathrm{O}$ on the surface of FeCo. With increasing $\mathrm{O}_{3}$ bubbling time, the intensities of both peaks decreased gradually, suggesting that the adsorbed water was replaced by ozone. Then, 2,4-D was added to the reaction system at different concentrations when $\mathrm{O}_{3}$ was bubbled for $10 \mathrm{~min}$ (Fig. 10). The

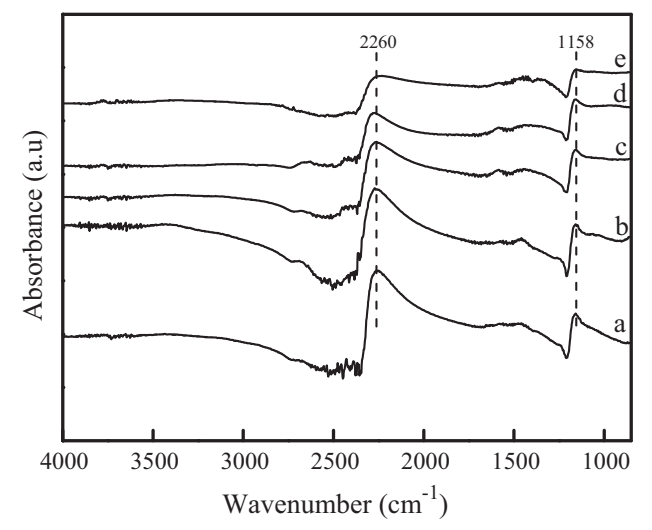

Fig. 9. ATR-FTIR spectra of FeCo suspended in $\mathrm{D}_{2} \mathrm{O}$ at pD 6 bubbling ozone for different times: (a) $0 \mathrm{~min}$, (b) $2 \mathrm{~min}$, (c) $5 \mathrm{~min}$, (d) $7 \mathrm{~min}$, (e) $10 \mathrm{~min}$. 


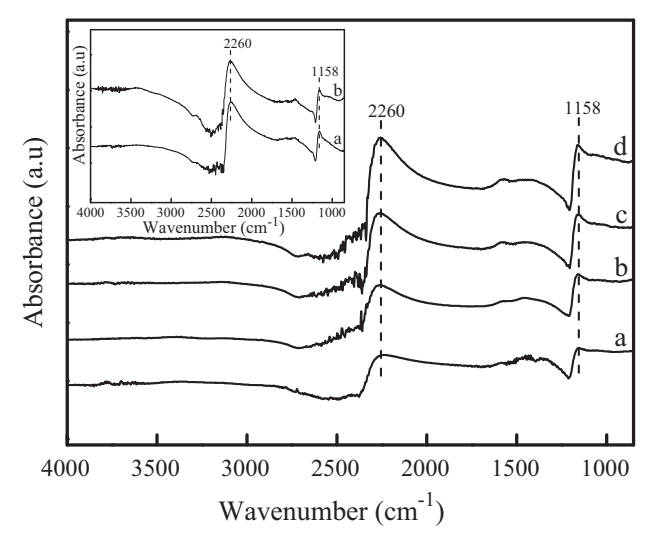

Fig. 10. ATR-FTIR spectra of FeCo suspended in $\mathrm{D}_{2} \mathrm{O}$ at pD 6 bubbling $\mathrm{O}_{3}$ for $10 \mathrm{~min}$ (a), then further react with different concentrations of 2,4-D for 5 min: (b) 2 ppm, (c) $8 \mathrm{ppm}$, (d) $20 \mathrm{ppm}$. The insert shows the ATR-FTIR spectra of FeCo suspended in $\mathrm{D}_{2} \mathrm{O}$ at $\mathrm{pD} 6$ (a) and pD $5.6(\mathrm{~b})$.

intensities of both peaks increased gradually with increasing 2 , 4-D concentration, indicating that the surface sites were gradually re-occupied by $\mathrm{D}_{2} \mathrm{O}$ with the consumption of ozone. The $\mathrm{pD}$ levels did not change greatly in any of the reactions, i.e., they ranged from 5.6 to 6.0 , which did not lead to a significant change in the intensity of adsorbed water, as seen in the inset of Fig. 10. Since phosphate is a stronger Lewis base than water, its presence inhibits the adsorption of water at the Lewis acid sites. Therefore, the effects of phosphate on the adsorption of $\mathrm{D}_{2} \mathrm{O}$ and ozone were observed on the surface of FeCo using in situ ATR-FTIR. As shown in Fig. S7 (Supporting Information), the intensity of the peak at $2260 \mathrm{~cm}^{-1}$ decreased and the peak at $1158 \mathrm{~cm}^{-1}$ disappeared with the addition of $5 \mathrm{mM}$ phosphate, while two new peaks belonging to phosphate vibrations appeared at 1149 and $1035 \mathrm{~cm}^{-1}$ [28]. By contrast, the addition of ozone did not affect the adsorption of phosphate, indicating that there was no significant ozone adsorption. These experimental results confirm that ozone was decomposed into reactive oxygen species by the adsorption of ozone and desorption of intermediates on the catalyst surface. In addition, $p C B A$ was chosen as a probe compound for the determination of hydroxyl radical $(\bullet \mathrm{OH})$ due to its high reactivity with ${ }^{\bullet} \mathrm{OH}$, but very low reactivity with other oxidants (i.e., $k_{\bullet \circ \mathrm{OH} / p \mathrm{CBA}}=5 \times 10^{9} \mathrm{M}^{-1} \mathrm{~s}^{-1}, k_{\mathrm{O}_{3} / p \mathrm{CBA}}=0.15 \mathrm{M}^{-1} \mathrm{~s}^{-1}$ ) [29]. Experiments were conducted at an acidic $\mathrm{pH}$ of 3 and neutral $\mathrm{pH}$ to investigate the $p C B A$ degradation in FeCo suspension (Fig. 11 and Fig. S8). About 20\% of the $p C B A$ was adsorbed on the

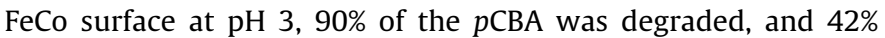
of the TOC was removed in the FeCo suspension with ozone at $20 \mathrm{~min}$, whereas about $63 \%$ of the pCBA was degraded, and $12 \%$ of the TOC was removed in ozone alone after the same amount of time. At $\mathrm{pH} 7$, no adsorption of $p C B A$ was observed on the catalyst; the $p C B A$ was removed completely within 4 min in the FeCo suspension with ozone, while the same result was obtained within $7 \mathrm{~min}$ in ozone alone, and the added catalyst also enhanced the TOC removal. No significant degradation of $p C B A$ was observed in the presence of tert-butanol (TBA) in any of the experiments. This indicated that the active species was mainly ${ }^{\circ} \mathrm{OH}$ radicals in both systems. With ozone alone, the effect of $\mathrm{pH}$ on the degradation of $p C B A$ predominantly contributed to the increased ozone decomposition into ${ }^{\bullet} \mathrm{OH}$ with the transition from an acidic to a neutral solution, while the increased $\bullet \mathrm{OH}$ formation enhanced the degradation of $p C B A$ in the FeCo suspension. The experimental data verified that ozone was adsorbed on the surface of FeCo while competing with water molecules in the aqueous phase, and then the ozone was converted into $\bullet \mathrm{OH}$, which diffused quickly to the bulk solution, accompanied by oxidation and reduction on the catalyst surface.
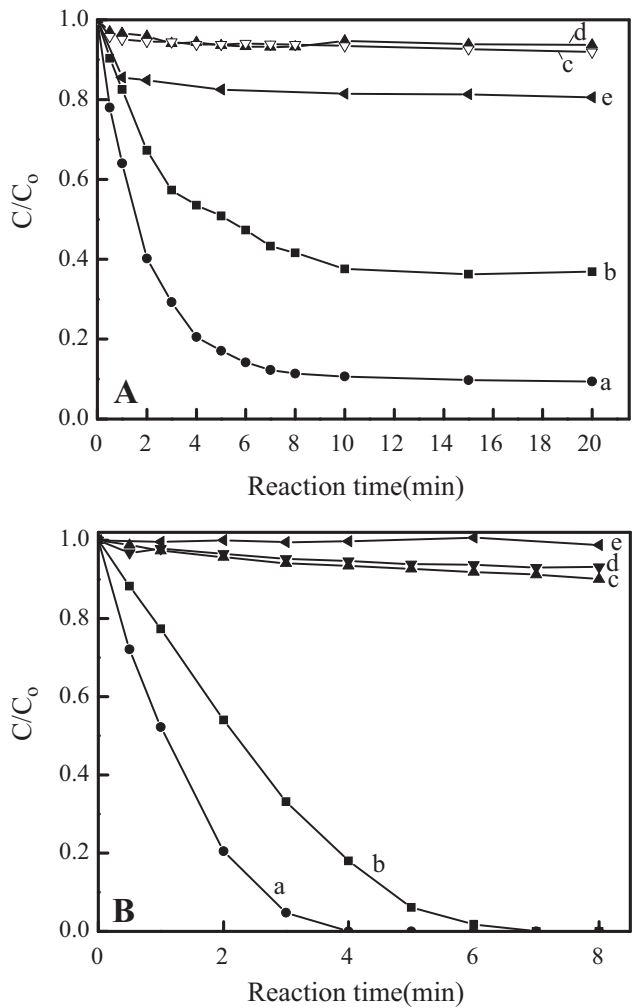

Fig. 11. The degradation of $p C B A$ in FeCo suspension with ozone at $\mathrm{pH} 3(\mathrm{~A})$ and 7 (B). For all panels: (a) FeCo, no catalyst with (b) or without (c) TBA, (d) FeCo/TBA, (e) FeCo adsorption ( $p C B A$ : $10 \mathrm{mg} \mathrm{L}^{-1}$, catalyst: $1 \mathrm{~g} \mathrm{~L}^{-1}$, gaseous ozone concentration: $30 \mathrm{mg} \mathrm{L}^{-1}$, scavenger concentration: $10 \mathrm{mM}$ ).

\section{Conclusions}

Magnetic cobalt-doped $\mathrm{Fe}_{3} \mathrm{O}_{4}$ showed highly efficiency and stability for the degradation and mineralization of the selected pollutants. For the first time, the competitive adsorption of $\mathrm{O}_{3}$ with $\mathrm{D}_{2} \mathrm{O}$ was observed at the surface of FeCo in the aqueous phase by in situ ATR-FTIR spectroscopy. Ozone was adsorbed on the surface of FeCo competing with water molecules in the aqueous phase, and then the ozone was converted into ${ }^{\bullet} \mathrm{OH}$, which diffused quickly to the bulk solution, accompanied by oxidation and reduction on the catalyst surface. A hydroxyl radical reaction mechanism was verified for the catalytic ozonation of selected pollutants in the FeCo suspension with ozone, and the introduction of Co enhanced the interfacial electron transfer, resulting in higher activity.

\section{Acknowledgment}

This work was supported by the National Natural Science Foundation of China (nos. 20977104, 21125731, 50908223, 50921064) and the 973 project (2010CB933600).

\section{Appendix A. Supplementary data}

Supplementary data associated with this article can be found, in the online version, at doi:10.1016/j.apcatb.2012.01.020.

\section{References}

[1] R.P. Schwarzenbach, B.I. Escher, K. Fenner, T.B. Hofstetter, C.A. Johnson, U. von Gunten, B. Wehrli, Science 313 (2006) 1072-1077.

[2] B. Kasprzyk-Hordern, M. Ziółek, J. Nawrocki, Appl. Catal. B: Environ. 46 (2003) 639-669.

[3] J. Nawrocki, B. Kasprzyk-Hordern, Appl. Catal. B: Environ. 99 (2010) 27-42. 
[4] S. Song, Z. Liu, Z. He, A. Zhang, J. Chen, Y. Yang, X. Xu, Environ. Sci. Technol. 44 (2010) 3913-3918.

[5] M. Sui, L. Sheng, K. Lu, F. Tian, Appl. Catal. B: Environ. 96 (2010) 94-100.

[6] C.T. Yavuz, J.T. Mayo, W.W. Yu, A. Prakash, J.C. Falkner, S. Yean, L.L. Cong, H.J. Shipley, A. Kan, M. Tomson, D. Natelson, V.L. Colvin, Science 314 (2006) 964-967.

[7] H. Liu, B. Qing, X. Ye, Q. Li, K. Lee, Z. Wu, Chem. Eng. J. 151 (2009) 235-240.

[8] H.-W. Chen, Y.-L. Kuo, C.-S. Chiou, S.-W. You, C.-M. Ma, C.-T. Chang, J. Hazard. Mater. 174 (2010) 795-800.

[9] A. Lv, C. Hu, Y. Nie, J. Qu, Appl. Catal. B: Environ. 100 (2010) 62-67.

[10] L. Yang, C. Hu, Y. Nie, J. Qu, Environ. Sci. Technol. 43 (2009) 2525-2529.

[11] S. Xing, C. Hu, J. Qu, H. He, M. Yang, Environ. Sci. Technol. 42 (2008) 3363-3368.

[12] W. Li, G.V. Gibbs, S.T. Oyama, J. Am. Chem. Soc. 120 (1998) 9041-9046.

[13] R. Radhakrishnan, S.T. Oyama, Y. Ohminami, K. Asakura, J. Phys. Chem. B 105 (2001) 9067-9070.

[14] K.M. Bulanin, J.C. Lavalley, A.A. Tsyganenko, Colloids Surf., A 101 (1995) 153-158.

[15] F.J. Beltrán, F.J. Rivas, R. Montero-de-Espinosa, Appl. Catal. B: Environ. 39(2002) 221-231.
[16] J. Ma, N.J.D. Graham, Water Res. 33 (1999) 785-793.

[17] T. Zhang, C. Li, J. Ma, H. Tian, Z. Qiang, Appl. Catal. B: Environ. 82 (2008) $131-137$.

[18] J. Lin, A. Kawai, T. Nakajima, Appl. Catal. B: Environ. 39 (2002) 157-165

[19] E. Brillas, J.C. Calpe, P.L. Cabot, Appl. Catal. B: Environ. 46 (2003) 381-391.

[20] R.R. Giri, H. Ozaki, S. Taniguchi, R. Takanami, Int. J. Environ. Sci. Technol. 5 (2008) $17-26$

[21] H. Xiao, Y. Xu, M. Yu, Q. Zhang, Environ. Technol. 31 (2010) 1295-1300.

[22] W.-J. Huang, G.-C. Fang, C.-C. Wang, Colloids Surf., A 260 (2005) 45-51.

[23] L.C.A. Oliveira, J.D. Fabris, R.R.V.A. Rios, W.N. Mussel, R.M. Lago, Appl. Catal. A: Gen. 259 (2004) 253-259.

[24] H.P. Boehm, Adv. Catal. 16 (1966) 179-274.

[25] K. Wandelt, Surf. Sci. Rep. 2 (1982) 1-121.

[26] W. Temesghen, P.M.A. Sherwood, Anal. Bioanal. Chem. 373 (2002) 601-608

[27] B.J. Tan, K.J. Klabunde, P.M.A. Sherwood, J. Am. Chem. Soc. 113 (1991) 855-861.

[28] M.I. Tejedor-Tejedor, M.A. Anderson, Langmuir 2 (1986) 203-210.

[29] H. Jung, H. Choi, Appl. Catal. B: Environ. 66 (2006) 288-294. 